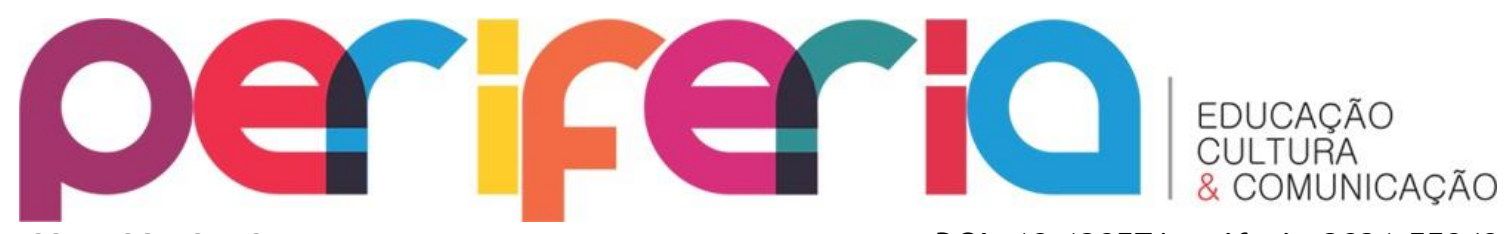

ISSN:1984-9540

DOI: 10.12957/periferia.2021.55949

\title{
FORMAÇÃO DE PROFESSORES PARA ESCOLAS RURAIS E A CERTIFICAÇÃO DOCENTE NO ESTADO DE SÃO PAULO EM 2010
}

\author{
Jaqueline Daniela Basso ${ }^{1}$ \\ Maria Cristina dos Santos ${ }^{2}$
}

\section{Resumo}

Historicamente a educação do campo surgiu a partir de demanda das populações do campo envolvidas na luta pela terra, sobretudo a partir de meados da década de 1980, quando o Movimento dos Trabalhadores Rurais sem Terra - MST se organizou e vem se constituindo, de lá para cá, como uma força impulsionadora exercendo pressão sobre o Estado para a garantia de direitos sociais, tanto o de acesso à terra e melhoria nas condições de vida dos trabalhadores do campo, quanto de acesso à educação escolar. Deste modo, objetivamos discutir algumas iniciativas de formação docente para o trabalho nas escolas rurais bem como os níveis de certificação docente no estado de São Paulo no final da primeira década do século XXI. Para isso, lançamos mão de revisão bibliográfica articulada à análise estatística a partir dos Microdados do Censo Escolar de 2010 que foram extraídos com auxílio do Software SPSS. A partir disto, concluímos que ocorreram avanços nas condições de formação de professores que atuam nas escolas do campo, de modo geral, do início do século XX para cá. Entretanto, iniciativas específicas, identificadas com o trabalho e as lutas daqueles que vivem no campo ainda são pontuais e resultantes das lutas dos movimentos sociais do campo, que ganharam força sobremaneira a partir de meados da década de 1980, portanto em um período histórico recente.

Palavras-chave: Direitos sociais; Educação do campo; Escolas do campo; formação docente; certificação docente.

\footnotetext{
1 Professora Adjunta na Universidade Estadual de Mato Grosso do Sul- UEMS. Professora Permanente do Programa de Pós-Gradução Mestrado Profissional em Educação da Universidade Estadual de Mato Grosso do Sul. Doutora e mestre em Educação pela Universidade Federal de São Carlos, na linha Estado, Política e Formação Humana. Pesquisadora no Grupo de Estudos e Pesquisas sobre Educação no Campo da Universidade Federal de São Carlos- GEPEC/ UFSCar e no Grupo Trabalho, Educação e Políticas Públicas G-TEPE/ UEMS. Instituição: Universidade Estadual de Mato Grosso do Sul. ORCID iD: https: / / orcid.org/0000-0002-4262-4140. E-mail: jaqueline.basso@uems.br

2 Professora Associada no Departamento de Educação da Universidade Federal de São Carlos DED/UFSCar. Professora do Programa de Pós-Graduação em Educação/UFSCar. Graduada em Ciências Sociais pela Associação Limeirense de Educação (1996) Mestre (2001) e Doutora em Educação pela Universidade Estadual de Campinas (2007). Pós-doutora em Educação; Ambiente e Sociedade; linha de pesquisa 'Dinâmica socioeconômica nos Ambientes urbano e rural; pela Universidade Estadual de Goiás (2017). Pós-doutora em Educação pelo Instituto de Educação da Universidade de Lisboa (2017) Membro do Grupo de Estudos e Pesquisas sobre Educação no Campo-GEPEC/UFSCar/HISTEDBR.ORCID iD: https://orcid.org/0000-0003-3130-9433 E-mail: cbezerra@ufscar.br
} 


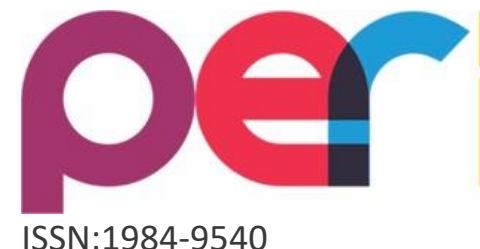

ISSN:1984-9540

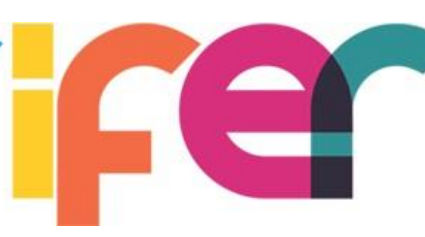

fer

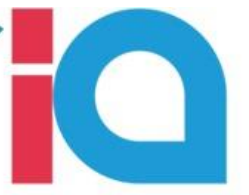

EDUCAÇÃO

CULTURA

\& COMUNICAÇÃO

DOI: $10.12957 /$ periferia.2021.55949

\title{
TEACHER TRAINING FOR RURAL SCHOOLS AND TEACHER CERTIFICATION IN THE STATE OF SÃO PAULO IN 2010
}

\begin{abstract}
Historically, the education of the field arose from the demand of the populations of the field involved in the struggle for land, especially from the mid-1980s when the Movement of Landless Rural Workers - MST was organized and has been constituting, since then, a driving force exerting pressure on the State to guarantee social rights , both access to land and improvement in the living conditions of field workers and access to school education. Thus, we aim to discuss some teacher training initiatives for work in rural schools as well as the levels of teacher certification in the state of São Paulo at the end of the first decade of the 21st century. For this, we used a bibliographic review articulated to the statistical analysis from the Microdata of the 2010 School Census that were extracted with the help of the SPSS Software. From this, we can conclude that there have been advances in the conditions of teacher training working in the schools of the field in general, from the beginning of the 20th century to here. However, specific initiatives, identified with the work and struggles of those who live in the field are still punctual and resulting from the struggles of the social movements of the field, which gained strength in the mid-1980s, therefore in a recent historical period.
\end{abstract}

Keywords: Social rights; Field education; Country schools; teacher training; teacher certification.

\section{CAPACITACIÓN DE MAESTROS PARA ESCUELAS RURALES Y LA CERTIFICACIÓN DOCENTE EN EL ESTADO DE SÃO PAULO EN 2010}

\section{Resumen}

Históricamente, la educación del campo surgió de la demanda de las poblaciones del campo involucradas en la lucha por la tierra, especialmente a mediados de la década de 1980, cuando se organizó el Movimiento de Trabajadores Rurales Sin Tierra - MST y ha estado constituyendo, desde entonces, una fuerza impulsora que ejerce presión sobre el Estado para garantizar los derechos sociales, tanto el acceso a la tierra como la mejora de las condiciones de vida de los trabajadores de campo y el acceso a la educación escolar. Por lo tanto, nuestro objetivo es discutir algunas iniciativas de formación de maestros para trabajar en escuelas rurales, así como los niveles de 


\section{periferio}

ISSN:1984-9540

DOI: $10.12957 /$ periferia.2021.55949

certificación de maestros en el estado de Sao Paulo a finales de la primera década del siglo XXI. Para ello, utilizamos una revisión bibliográfica articulada al análisis estadístico de los Microdatos del Censo Escolar 2010 que se extrajeron con la ayuda del Software SPSS. De esto, podemos concluir que ha habido avances en las condiciones de formación del profesorado trabajando en las escuelas del campo en general, desde principios del siglo XX hasta aquí. Sin embargo, las iniciativas específicas, identificadas con el trabajo y las luchas de quienes viven en el campo siguen siendo puntuales y resultantes de las luchas de los movimientos sociales del campo, que ganaron fuerza a mediados de la década de 1980, por lo tanto, en un período histórico reciente.

Palabras clave: Derechos sociales; Educación de campo; Escuelas de campo; formación de maestros; certificación de maestros.

\section{Introdução}

Historicamente a educação do campo surgiu a partir de demanda das populações do campo envolvidas na luta pela terra, sobretudo a partir de meados da década de 1980, quando o Movimento dos Trabalhadores Rurais sem Terra - MST se organizou e vem se constituindo, de lá para cá, como uma força impulsionadora exercendo pressão sobre o Estado para a garantia de direitos sociais, tanto o de acesso à terra e melhoria nas condições de vida dos trabalhadores do campo, quanto de acesso à educação escolar. Entretanto, a discussão acerca da necessidade e da importância da educação rural, além de formação específica de professores para atuar nas escolas rurais, é anterior, remonta ao início do século XX, e foi marcado pelo embate entre dois diferentes projetos para o desenvolvimento do Brasil: de um lado, estavam aqueles que defendiam o processo de urbanização e industrialização; e, de outro, aqueles que desejavam a manutenção da ordem agrária exportadora que caracterizava o país naquele período.

Em meio a esse embate, um grupo de pensadores e educadores iniciou o movimento chamado Ruralismo Pedagógico que via na educação a capacidade de conter o êxodo da população do meio rural para as cidades e uma das ferramentas para isso era a formação de professores afeitos à vida e ao trabalho no campo (BASSO,2013; BASSO, 2018; BEZERRA NETO, 2003; MENUCCI, 1946). Décadas depois, tanto o MST quanto o Movimento por uma Educação Básica do Campo guardam 


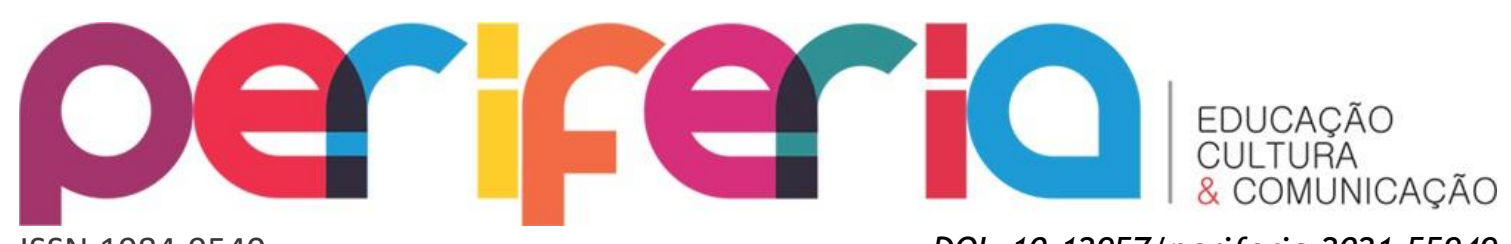

ISSN:1984-9540

DOI: $10.12957 /$ periferia.2021.55949

elementos herdados do Ruralismo Pedagógico ao defender a formação específica para os professores que lecionam em escolas em áreas rurais.

Nesse contexto, o presente trabalho, resultante de pesquisa em nível de mestrado, tem por objetivo discutir algumas iniciativas de formação docente para o trabalho nas escolas rurais, bem como os níveis de certificação docente no estado de São Paulo, no final da primeira década do século XXI. Para tanto, contextualizaremos o processo de luta por uma formação específica de professores para as escolas rurais, realizando um breve resgate histórico acerca do Ruralismo Pedagógico; em seguida, discutiremos algumas iniciativas do período histórico recente nesse sentido; por fim, apresentaremos e analisaremos dados produzidos sobre os níveis de certificação daqueles professores que atuavam em escolas no campo no Estado de São Paulo no ano de 2010.

Para isso lançamos mão de revisão bibliográfica, que segundo Gil (2002, p. 44) “é desenvolvida com base em material já elaborado constituído principalmente de livros e artigos científicos" articulado com análise estatística a partir dos Microdados do Censo Escolar de 2010 que foram extraídos com auxílio do Software SPSS, escolha metodológica que se justifica, uma vez que de acordo com Gamboa (2009, p. 106) "na pesquisa em ciências sociais, frequentemente são utilizados resultados e dados expressos em números. Porém, se interpretados e contextualizados à luz da dinâmica social mais ampla, a análise torna-se qualitativa".

Destarte, os resultados da pesquisa serão apresentados do seguinte modo: iniciaremos com a contextualização do tema realizando um breve histórico acerca do Ruralismo Pedagógico; na sequência, trataremos de algumas iniciativas voltadas à formação de professores, sobretudo aquelas apoiadas pelos Movimentos por uma Educação Básica do Campo e dos Trabalhadores Rurais sem Terra; finalizaremos expondo e discutindo os indicadores levantados acerca dos níveis de certificação dos professores que atuavam nas escolas do campo no Estado de São Paulo, no final da primeira década do século XXI, mais precisamente no ano de 2010. 


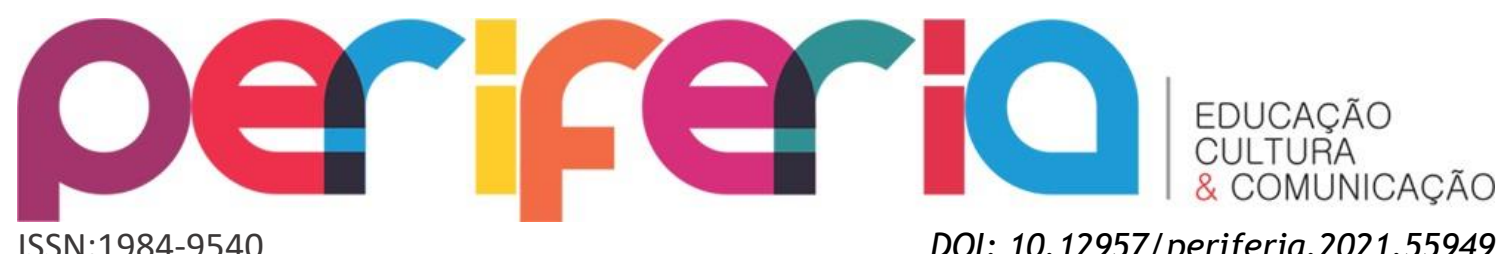

1. O Ruralismo Pedagógico e a defesa da formação específica de professores para o campo

Desde o fim do século XIX, os professores relutavam em lecionar nas áreas rurais, dada a distância que deveria ser percorrida até as escolas, em estradas de chão batido, sem meios de transporte adequados. A precariedade da infraestrutura das escolas e as turmas unidocentes ${ }^{3}$ também eram fatores que colaboravam para esta situação. Porém, os adeptos ao Ruralismo Pedagógico, que se debruçaram sobre as problemáticas da educação rural enxergavam outra questão, a inadequação da formação dos docentes para a realidade do meio rural (BASSO, 2013).

No início do século $X X$, disseminou-se a concepção de que a população rural não se interessava pela escola, o que foi muito útil tanto para o Estado, que assim justificava a inferioridade dos investimentos na educação rural, quanto para os docentes, que buscavam fugir da hostilidade do ambiente rural e das más condições de trabalho lá encontradas (SOUZA, 2009, p. 150).

Contudo, nas décadas de 1920 e 1930, pensadores ruralistas buscaram evidenciar os problemas da educação rural, embasados em projetos mais abrangentes para a sociedade brasileira. Naquele período, diferentes projetos de modernização da sociedade estavam em jogo, de um lado, tais projetos eram representados pelas indústrias, e de outro, pela economia agrária, já alicerçada nacionalmente, aparecia como a melhor opção (SOUZA, 2009, p. 150).

Dentre os pedagogos ruralistas estava Sud Menucci, o mais conhecido do movimento no Estado de São Paulo. Assim como Menucci, os demais educadores daquele movimento criticavam o modelo único de escola primária existente no estado, que por estar alicerçado nos valores e cultura urbanos, não serviria ao homem do campo, colaborando para o êxodo rural. Desta maneira, os ruralistas pedagógicos viam a criação da escola rural como uma forma de fixar o homem no campo (SOUZA, 2009, p. 150).

Sud Menucci não repudiava o valor da instrução e da educação, mas a forma como ela acontecia no campo, visto que, a repulsa do próprio campesino evidenciaria

3 Situação em que um único professor atende uma turma com alunos em diferentes níveis de aprendizagem e idades, hoje chamada de multissérie. 


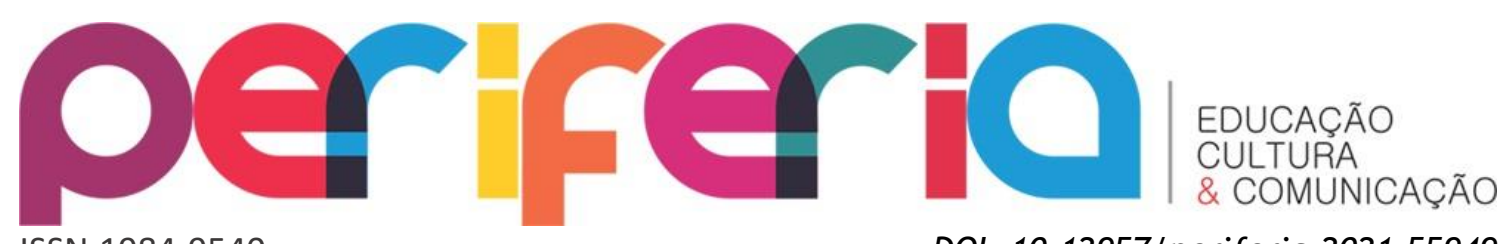

ISSN:1984-9540

DOI: $10.12957 /$ periferia.2021.55949

sua inadequação. Naquele contexto, a figura do mestre aparecia como ameaçadora, justamente por sua mentalidade calcada em valores urbanos (MENUCCI, 1946).

A partir disto, em 1932, foi elaborada uma proposta de Reforma do Ensino Rural para o Estado de São Paulo, que defendia a formação de novos educadores, com mentalidade coerente com a realidade e necessidades do campo, para isso empreendiam o estabelecimento das Escolas Normais Rurais, o que dividiria o professorado em duas classes, a urbana e a rural, quiçá uma terceira classe, a dos professores litorâneos. As Escolas Normais Rurais se organizariam em três pontos de vista: o pedagógico, o sanitário e o higiênico, o que requereria três tipos de docentes, os professores propriamente ditos, os professores-médicos e os professores-agrônomos (MENUCCI, 1946, p. 141). "Tais escolas têm de formar professores quase hostis à vida citadina, perenemente preocupados com a maior eficiência do campo e de tal modo que se constituam em líderes do núcleo em que vão servir" (MENUCCl, 1946, p. 142).

Embora tenham sido propostas, as Escolas Normais Rurais não chegaram a se materializar no Estado de São Paulo, mas o Ruralismo Pedagógico se fez presente em diferentes inciativas educacionais nas quatro primeiras décadas do século XX, das quais podemos citar: os Cursos de Especialização Agrícola nos Municípios paulistas de São Carlos, Casa Branca, Espírito Santo do Pinhal e São Manoel voltados à formação continuada de professores que lecionavam em escolas rurais; as Escolas Agrícolas, a exemplo da Escola Superior de Agricultura "Luiz de Queiroz" - Esalq/Piracicaba, hoje componente da Universidade de São Paulo e os Clubes Agrícolas Escolares. Todas essas iniciativas levaram a cabo os ideais ruralistas, sobretudo por meio da inclusão de práticas agrícolas, agropecuárias e noções de higiene em seus currículos (BASSO, 2018).

Embora os ruralistas tenham lutado por uma educação identificada com o homem do campo e sua realidade laboral e tenham surgido iniciativas educacionais, como as mencionadas, pouca coisa mudou na educação que ocorre no campo, visto que, sobretudo após os anos 1950, as políticas econômicas brasileiras se voltaram para a industrialização e com ela, à urbanização do país.

A industrialização e investimentos em infraestrutura urbana, a partir das décadas de 1950 e 1960, fizeram com que muitos trabalhadores analfabetos saíssem 


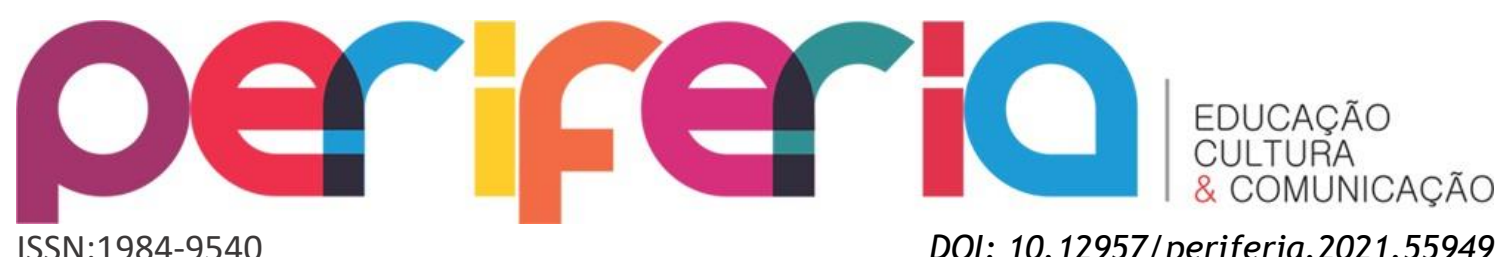

do campo e fossem para a cidade, o que provava que a leitura não era necessária para o ingresso neste novo mercado de trabalho, derrubando, portanto, o discurso dos ruralistas de que a má formação escolar colaborava para a expulsão do homem do campo. O processo de modernização conservadora do campo brasileiro, a partir da década de 1970, foi outra condição que seguramente colaborou para o avanço do êxodo rural (BEZERRA NETO, 2003, p. 54).

Assim, desde o final do século XIX a educação não tem sido prioridade nacional, tanto no campo quanto na cidade. Devido ao fato de a economia brasileira ser predominantemente agrária, esperava-se que o campo apresentasse boas condições de vida e acesso a bens sociais como a educação, porém, o que percebemos foi uma diferenciação histórica em relação à educação oferecida na cidade. Daí a necessidade e a importância de movimentos que lutem não só pelo direito à posse e uso da terra, mas pela educação e outros serviços sociais que são garantidos àqueles que vivem nas cidades.

\section{Os cursos de formação docente do Instituto de Educação Josué de Castro, o} curso de Pedagogia da terra e as Licenciaturas em Educação do Campo

É nesse contexto de luta por direitos sociais às populações do campo que se situam o Movimento dos Trabalhadores Rurais sem Terra (MST) e o Movimento por Uma Educação Básica do Campo. Ambos defendem uma educação específica para o campo e têm contribuído para as discussões, tanto em âmbito acadêmico, quanto social e político; têm buscado a inclusão da educação do campo nas agendas públicas. O Movimento dos Trabalhadores Rurais Sem Terra - MST foi criado oficialmente em 1984, colocando em pauta a luta dos trabalhadores rurais pela terra e a necessidade de uma educação no próprio campo identificada com as causas e necessidades destes trabalhadores (BEZERRA NETO, 2003).

Movido pela busca da construção de uma sociedade igualitária, o MST acredita que a redistribuição das terras ociosas para a massa de trabalhadores rurais excluídos é a melhor opção para a melhoria das condições de vida destes trabalhadores, para a produção de alimentos via agricultura familiar e, consequentemente, para a distribuição da renda nacional. "Daí a insistência na luta pela manutenção do homem 


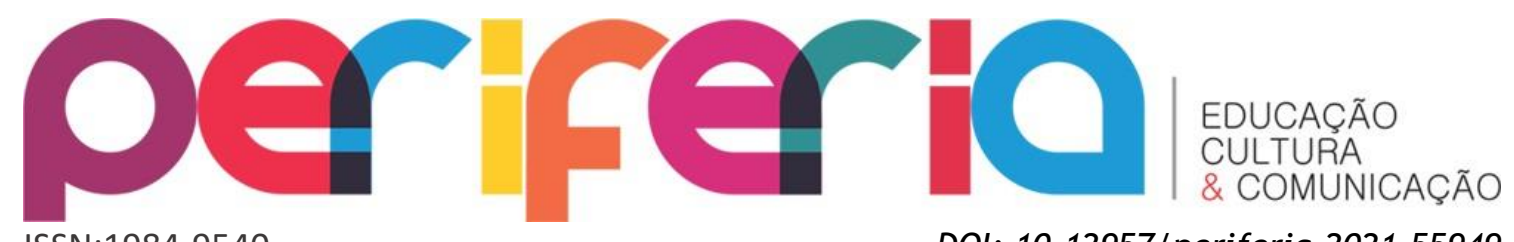

ISSN:1984-9540

DOI: $10.12957 /$ periferia.2021.55949

no campo, através de uma Reforma Agrária que distribua a propriedade da terra" (BEZERRA NETO, 2003, p. 145).

De acordo com João Pedro Stédile (1997, p. 9) a preocupação do MST com a educação foi sendo construída como um processo, em meio à luta pela terra, não houve imposição teórica, as práticas educativas começaram a acontecer no interior do movimento a partir da percepção de seus membros da importância e da necessidade da educação na vida dos trabalhadores do campo. À medida que a conquista da terra foi se tornando realidade, o movimento cresceu e amadureceu, então, percebeu-se o desafio que representaria a busca por educação nos assentamentos.

Frente a esse desafio, em 1997, o MST realizou o 10 ENERA - Encontro Nacional de Educadores e Educadoras da Reforma Agrária, ao fim daquele encontro surgiu a primeira Conferência Nacional Por uma Educação Básica do Campo, que se tornou um espaço de reflexão e mobilização popular em favor de uma educação que, em seus conteúdos e metodologia, considerasse a especificidade do campo (KOLLING; NÉRY; MOLINA, 1999, p. 13).

Para o Movimento por uma Educação Básica do Campo, a educação do campo tem o significado de uma educação voltada para todos os que trabalham no campo e que não é suficiente que a escola esteja no campo apenas, mas que existam escolas do campo, isto é, escolas com projetos político-pedagógico coerentes com as causas, desafios, sonhos, história e cultura do povo trabalhador do campo.

Nesse contexto, uma das críticas realizadas tanto pelo MST quanto pelo Movimento por um Educação Básica do Campo se refere à inadequação da formação dos professores que atuam nas escolas do campo, que formados nos moldes urbanos, não colaborariam para a valorização do modo de vida e trabalho nas áreas rurais, concepção que parece derivar do Ruralismo Pedagógico, a pouco tratado.

Visando sanar essa denunciada inadequação, as discussões lideradas por estes dois movimentos originaram iniciativas de formação docente específicas para as escolas do campo, dentre elas, podemos citar os cursos de formação docente do Instituto de Educação Josué de Castro e o curso de Pedagogia da Terra, voltados para assentados da reforma agrária. 


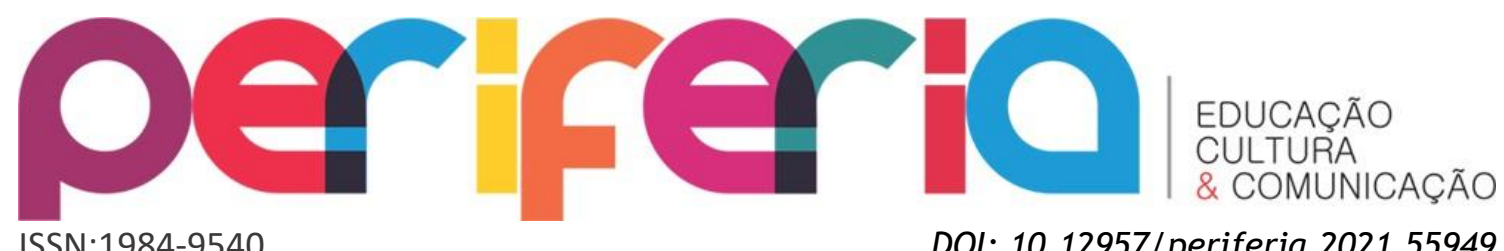

O Instituto de Educação Josué de Castro - IEJC é uma escola de formação do MST, abrigada pelo ITERRA - Instituto Técnico de Capacitação e Pesquisa da Reforma Agrária, em Veranópolis, Rio Grande do Sul, onde vêm sendo desenvolvidos cursos de formação docente em nível médio e um dos cursos de Pedagogia da Terra em parceria com a Universidade Estadual do Rio Grande do Sul. O curso atende demandas de diversos movimentos sociais do campo, desde o ano de 2002 (CASAGRANDE, 2007, p. 23).

Em 2007, o IEJC oferecia, além do curso de Pedagogia da Terra, cursos em nível médio e qualificação profissional, como o de Técnico em Administração de Cooperativas, Normal de Nível Médio (Magistério), técnico em Saúde Comunitária, Educação de Jovens e Adultos em Nível Médio e Qualificação Profissional em Comunicação Social (CASAGRANDE, 2007, p.145). Percebemos que, embora a Lei de Diretrizes e Bases da Educação Nacional, Lei 9.394/96 em 1996 tenha preconizado a formação docente em nível superior, o Instituto ainda oferece o Normal em Nível Médio, o que poderia ser considerado um retrocesso. Entretanto, se considerarmos a dificuldade de acesso das camadas populares às instituições de Ensino Superior, o Magistério aparece como uma alternativa para a formação dos professores, neste caso, identificados com a realidade do campo, que desejam atuar nos acampamentos e assentamentos da reforma agrária.

O Magistério e os demais cursos do IEJC apresentam uma metodologia diferenciada, Nair Casagrande, ao analisar o documento do ITERRA intitulado “Instituto de Educação Josué de Castro- Método Pedagógico" constatou que:

O primeiro destaque exposto é que o método pedagógico do Instituto
de Educação não é fechado, dogmatizado, visto que se encontra em
constante gestação através dos educadores e educandos que dele
participam. Além disso, sua teoria tem sido produzida no calor da
vida escolar, numa escola real, em movimento onde o método passa
por um fazer e refazer a partir da Pedagogia do MST (CASAGRANDE,
2007, p. 147).

Nair Casagrande (2007) nos mostra que o trabalho pedagógico desenvolvido no Instituto de Educação Josué de Castro, norteado pelas concepções pedagógicas do MST, extrapola as imposições metodológicas dos governos Federal e Estadual e conta com a participação dos docentes e discentes no processo de constante renovação metodológica. Desta maneira, promove a formação docente de modo 


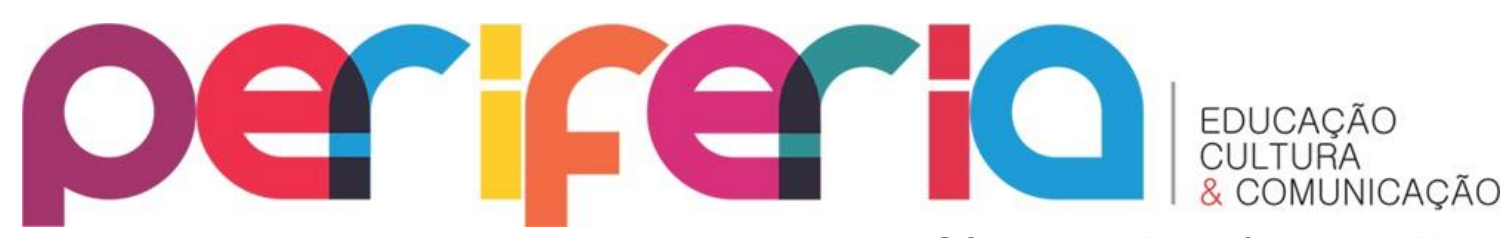

ISSN:1984-9540

DOI: $10.12957 /$ periferia.2021.55949

contextualizado com a realidade escolar dos assentamentos e acampamentos, alinhada com os anseios do Movimento dos Trabalhadores Rurais Sem Terra.

Este conceito de escola em movimento também está presente no curso de Pedagogia da Terra, que foi a denominação dada ao curso de formação de educadores do MST, que compõe as ações do movimento para a consolidação de suas propostas educativas. Trata-se de um curso superior implementado em parceria com instituições federais de Ensino Superior e que já se alicerçou em vários Estados brasileiros, conforme Gonsaga (2009, p. 20):

Considerando a preocupação do Movimento com a educação das escolas de assentamento e acampamento, o objetivo do curso é formar educadores para atuar nas séries iniciais do Ensino Fundamental. 0 curso funciona em regime de alternância. Essa Pedagogia se caracteriza pela alternância dos estudantes entre a escola e sua propriedade, sua casa, ou como no caso dos educadores do MST, seu trabalho nas escolas de assentamento e acampamento. A essência da Pedagogia da Alternância está no fato de a mesma proporcionar a troca de saberes deste último, em seu conhecimento prático. No Brasil a Alternância tem sido um instrumento de grande relevância, no sentido de resgatar os valores, costumes e modo de vida das famílias camponesas, inserindo-as num contexto em que se colocam como sujeitos transformadores e construtores de seu próprio meio.

O curso de Pedagogia da Terra tem a práxis como ferramenta para a formação dos educadores do campo e utilizam, em alternância, tanto as instituições de ensino superior como o ambiente em que vivem como fonte para a obtenção de conhecimentos formais e informais. Os conhecimentos informais estão diretamente ligados à cultura, aos costumes e ao modo de vida do campo, são eles os elementos responsáveis pela formação da identidade dos educadores com a realidade rural, almejada pelos movimentos sociais rurais.

Eliana Gonsaga (2009, p. 21) complementa ainda esta questão, afirmando que,

não basta apenas o conhecimento teórico, a proposta de educação do MST busca fazer a combinação da teoria com a prática, visando proporcionar aos sujeitos as condições devidas que os levem a um nível de amadurecimento capaz de torná-los seres conscientes de sua condição, sujeitos que tenham consciência de classe e que percebam que a conquista da terra não basta, que é necessário, portanto, desencadear outras lutas para que tenham condições de vida reais e dignas. 


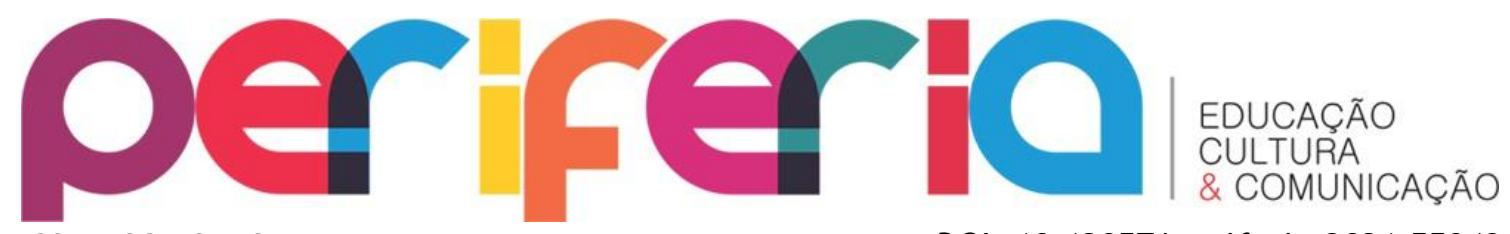

ISSN:1984-9540

DOI: $10.12957 /$ periferia. 2021.55949

Percebemos que o MST busca uma educação diferenciada daquela que é oferecida pelo Estado neoliberal, que seja capaz de criar nos indivíduos a consciência da luta de classes que permeia a sociedade capitalista e oprime a massa trabalhadora. Embora esta seja uma postura crítica, Luiz Bezerra Neto (1998, p. 136) nos alerta que,

o MST opta, portanto, por forjar uma nova maneira de ensinar a partir da contribuição de pedagogos que, no passado ou no presente, estiveram engajados, ou pelo menos posicionados politicamente nos partidos de esquerda. Buscando aproveitar tudo aquilo que entende como positivo em uma variada gama de educadores, de diferentes correntes pedagógicas, do existencialismo cristão de Paulo Freire, até o construtivismo de Piaget ou o marxismo de Makarenko, se constrói um ecletismo metodológico, através do qual as crianças dos acampamentos e assentamentos devem construir seus saberes.

Apesar de se propugnar uma pedagogia contra-hegemônica, as propostas educacionais do movimento são marcadas por uma diversidade de influências metodológicas, e isto se faz presente também no curso de Pedagogia da Terra. Desta maneira, o curso aparece como alternativa para a formação dos docentes que atuam em assentamentos e acampamentos da reforma agrária, oferecendo uma formação eclética, porém identificada com a realidade dos trabalhadores assentados, alinhada com as reivindicações dos movimentos sociais e consequentemente, com os traços ruralistas nele presentes.

Além da Pedagogia da Terra, é imperativo mencionarmos as Licenciaturas em Educação do Campo que ocorrem no âmbito do Programa de Apoio à Formação Superior em Licenciatura em Educação do Campo - PROCAMPO, desde 2007, por meio de parcerias entre Ministério da Educação - MEC e Universidades Federais brasileiras. As primeiras experiências aconteceram nos Estados de Minas Gerais, Distrito Federal, Sergipe e Bahia. Nos anos de 2008 e 2009, depois de pressões dos movimentos sociais, o MEC lançou editais que deram origem a quarenta e dois destes cursos em Universidades Federais de todo o país (MOLINA, 2017).

Os cursos de Licenciatura em Educação do Campo, assim como os outros dois discutidos, podem ser considerados uma vitória das populações do campo em relação à possibilidade de sua formação em nível superior, visto que: 


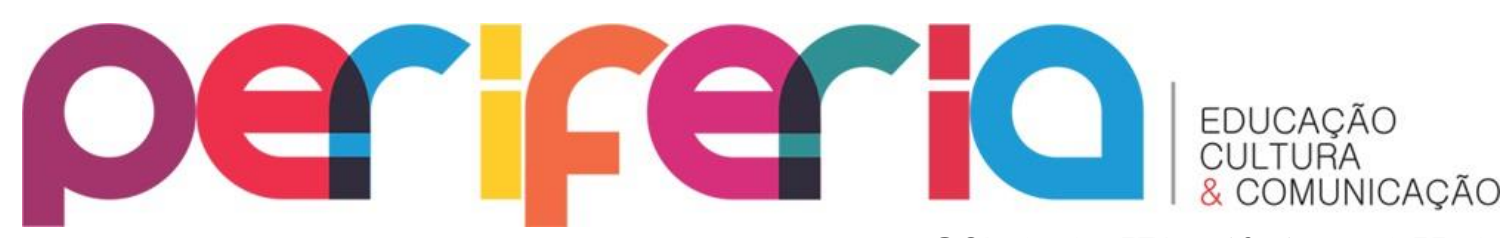

ISSN:1984-9540

DOI: $10.12957 /$ periferia.2021.55949

[...] essas Licenciaturas têm uma marca constitutiva fundamental, que é o fato de já terem sido projetadas assumindo uma posição de classe, rompendo tradicionais paradigmas que afirmam a possibilidade da neutralidade da produção do conhecimento científico e das políticas educacionais. As LEdoCs são planejadas considerando-se a luta de classes no campo brasileiro e colocando-se como parte e ao lado do polo do trabalho, assumindo e defendendo a educação como um direito e um bem público e social (MOLINA, 2017, p. 590).

Portanto, percebemos que as iniciativas de formação docente aqui materializadas nos cursos de formação docente do IEJC, na Pedagogia da Terra e nas Licenciaturas em Educação do Campo se encontram pareados a uma proposta de educação do campo, identificada com as lutas dos trabalhadores rurais pelo acesso à terra e aos demais direitos sociais. Cientes da existência destas iniciativas voltadas à formação de professores para as escolas do campo, nos dedicaremos, adiante, à análise dos indicadores dos níveis de certificação docente no estado de São Paulo, que nos permitirão visualizar quem eram os professores que atuavam nas escolas rurais naquele estado há uma década.

\section{Os níveis de certificação docente no Estado de São Paulo em 2010: algumas considerações}

Por todo o exposto, ficou evidente que a formação de professores para as escolas do campo é uma problemática que permeia os debates educacionais desde o início do século XX e tem desencadeado iniciativas que a contemplem ao longo desse período histórico. No entanto, os maiores avanços em termos de formação de educadores para as escolas situadas em áreas rurais se deram a partir do final do século XX e primeiras décadas do século XXI, pressionados pelos movimentos sociais que se organizam em torno da luta pela terra e por educação no campo. Esse fato nos instigou a investigar como estavam os níveis de certificação dos professores do Estado de São Paulo no final da primeira década do século XXI.

A certificação é um dos fatores que incidem sobre as condições de trabalho docente, sobre isso, Alvana Maria Bof (2006, p. 35) esclarece que:

a condição de trabalho desses profissionais tem se precarizado cada vez mais. No caso específico da área rural, além da baixa qualificação 


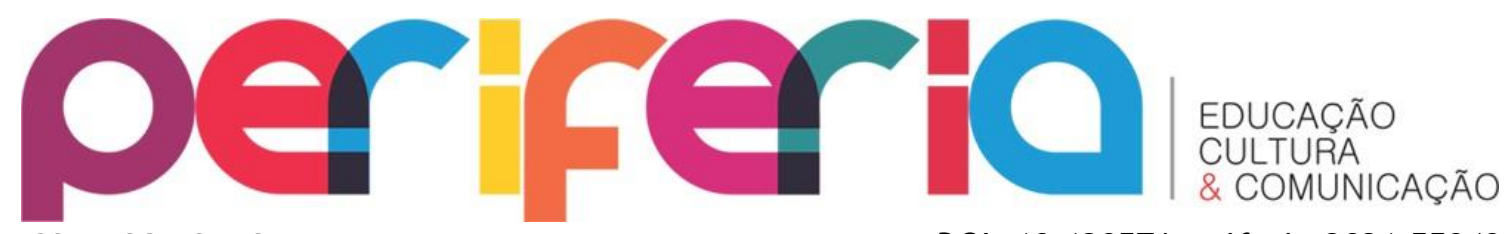

ISSN:1984-9540

DOI: $10.12957 /$ periferia.2021.55949

e salários inferiores aos da zona urbana, eles enfrentam, entre outras, as questões de sobrecarga de trabalho, alta rotatividade e dificuldade de acesso à escola, em função das condições das estradas e da falta de ajuda de custo para locomoção.

Com base em indicadores do Instituto Nacional de Pesquisas Educacionais Anísio Teixeira (INEP), referentes ao ano de 2002, Alvana Maria Bof (2006, p. 35) continua afirmando que,

o nível de escolaridade dos professores revela, mais uma vez, a condição de carência da zona rural. No ensino fundamental de 1-a a $4^{\text {a }}$ série, apenas $9 \%$ apresenta formação superior, enquanto na zona urbana este contingente representa $38 \%$ dos docentes. 0 percentual de docentes com formação inferior ao ensino médio corresponde a 8,3\% na zona rural, indicando a existência de 18.035 professores sem habilitação mínima para o desempenho de suas atividades. Isso sem considerar aqueles que, apesar de terem formação em nível médio, não são portadores de ensino médio normal. Na zona urbana esse contingente corresponde a $0,8 \%$. Nas séries finais do ensino fundamental, o percentual de docentes com apenas o ensino médio completo corresponde a $57 \%$ do total.

Os dados analisados por Bof nos mostram a realidade da formação daqueles docentes que atuavam no campo em um passado próximo (2002), evidenciando que, naquele período, seis anos após a promulgação da LDB, que prioriza a formação docente em nível superior, menos de dez por cento dos professores brasileiros que ensinavam em turmas rurais, no primeiro ciclo do Ensino Fundamental, possuíam certificação em nível superior. Todavia, a autora nos traz outro dado ainda mais alarmante, cerca de oito por cento dos professores do campo não possuíam sequer o ensino médio completo, o que demonstra que nas áreas rurais a figura do professor leigo ainda existe.

Visando comparar a realidade brasileira demonstrada pelos indicadores do Inep de 2002, realizamos a coleta de dados estatísticos dos Microdados do Censo Escolar de 2010 com o uso do Software SPSS que nos permitiu a extração e cruzamento de indicadores, não só dos níveis de formação dos professores que lecionavam em áreas rurais, mas de todo o professorado paulista atuante naquele ano. 


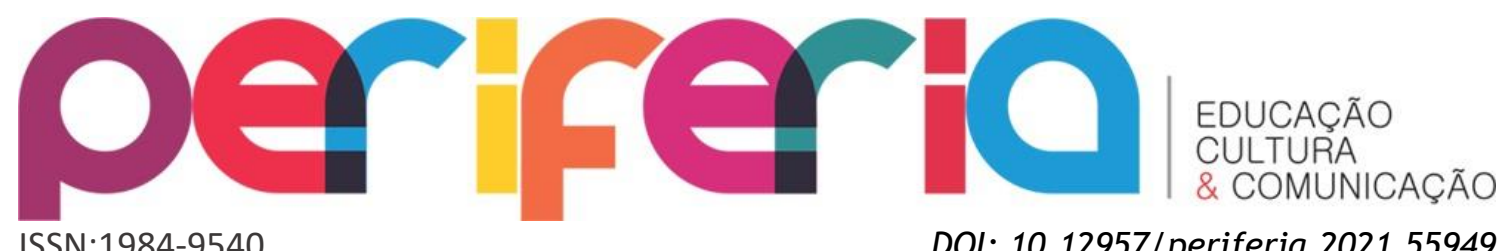

A partir da coleta, elaboramos uma tabela com os valores absolutos e representações percentuais dos diferentes níveis de formação docente, nas áreas rurais e urbanas. Se observássemos apenas os valores absolutos, desconsiderando a representação percentual, poderíamos realizar uma primeira análise equivocada, visto que o número de docentes no campo é bem menor do que no meio urbano, vejamos:

Tabela 1 - Frequência escolaridade docentes no Estado de São Paulo comparativo meio urbano e rural - 2010 — valores absolutos e percentuais

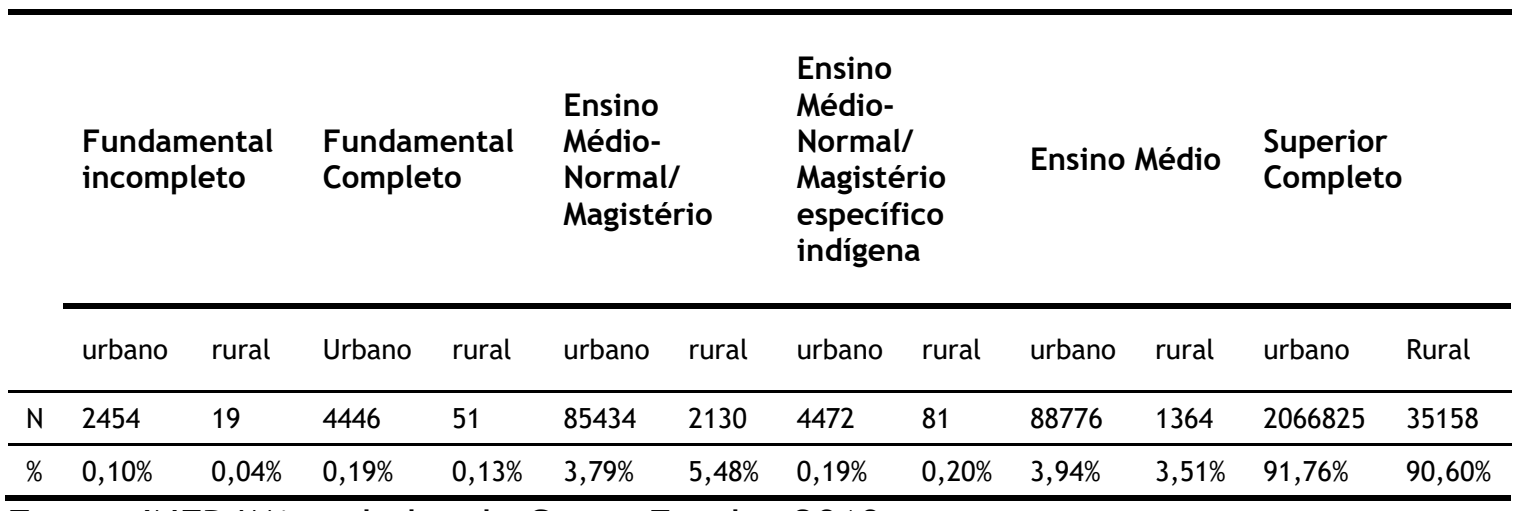

Fonte: INEP/Microdados do Censo Escolar 2010

A análise das representações percentuais demonstra que, a diferença do nível de certificação entre os educadores que atuavam no campo e nas cidades em 2010, era pequena. Mesmo nos embasando em dados anteriores, se compararmos o nível de certificação docente no campo em 2002 aos dados aqui apresentados, veremos que o Estado de São Paulo apresenta um elevado índice de professores graduados, seja nas cidades ou no campo, se comparado à média do país. Assim, no ano de 2010, no Estado de São Paulo, os professores que trabalhavam em escolas do campo possuíam nível de certificação semelhante ao daqueles que têm as escolas das cidades como local de trabalho.

Os microdados do Censo Escolar nos mostram que, em 2010, o Estado de São Paulo possuía uma parcela pequena, menos de cinco por cento, tanto nas cidades quanto no campo, de professores leigos, ou seja, aqueles que não possuem a formação mínima exigida para o exercício da docência, que é o curso Normal em Nível Médio; desta maneira, são considerados leigos aqui, os que possuem Ensino Fundamental incompleto, completo e Ensino Médio. Podemos perceber que, em 


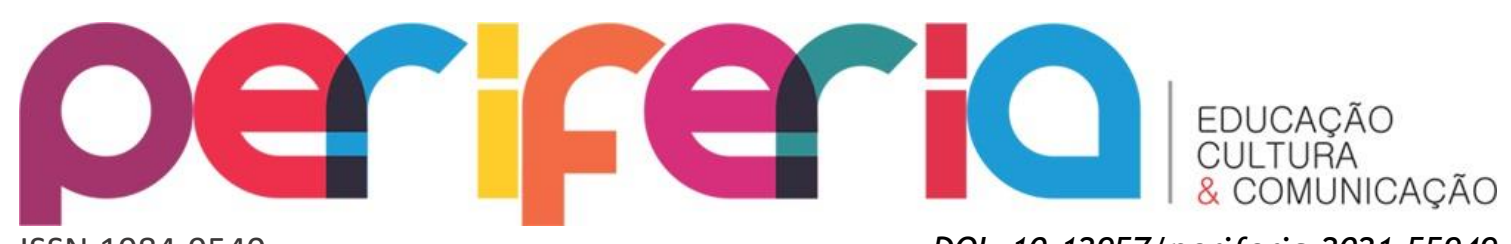

ISSN:1984-9540

DOI: $10.12957 /$ periferia.2021.55949

níveis percentuais, existiam naquele ano, menos professores leigos nas cidades do que no campo.

Ao compararmos os professores com Ensino Médio-Normal e Ensino MédioNormal específico para a educação indígena, que acontece no campo, veremos que no campo há uma parcela maior de professores com este nível de formação, 5,68\%, enquanto no meio urbano ela representa $3,98 \%$. Todavia, a maior parte dos professores paulistas possuía certificação em nível superior, 91,76\% dos que atuam nas das cidades e $90,60 \%$ daqueles que estão no campo, ou seja, algo em torno de um por cento de diferença, em detrimento ao ensino que acontece no campo.

Porém, não podemos perder de vista as constatações de Alvana Maria Bof (2006, p. 40), que embasadas em dados referentes ao ano de 2002, mostraram-nos um Brasil no qual os professores do campo apresentavam baixos níveis de escolarização, assim a autora alerta que os professores que atuavam na Educação Básica no campo, naquele ano, eram, "em sua grande maioria, os menos qualificados e os que recebem os menores salários".

Embora os professores do Estado de São Paulo tenham bons níveis de certificação não podemos tratar estes indicadores como sinônimo de formação de qualidade, daí utilizarmos neste trabalho certificação ao invés de qualificação docente. Este é um problema que atinge todo o Brasil, com a exigência da LDB para que a formação docente se dê em nível superior, houve uma enorme expansão nos cursos de Pedagogia da rede privada de universidades que formam professores de modo aligeirado e, consequentemente, questionável. Esta situação se agrava ainda mais quando a formação inicial se dá à distância.

Acácia Kuenzer (1999, p. 179) considera que a questão da qualidade da formação em nível superior no Brasil perpassa pela autonomia didática das instituições de ensino, uma vez que a LDB substituiu os currículos mínimos pelas diretrizes curriculares, que por serem rígidos e burocráticos não mais se enquadrariam na realidade educacional, pelas diretrizes curriculares. Estas diretrizes contêm princípios gerais, que permitem a flexibilização das propostas das instituições superiores de ensino, de acordo com o mercado e as necessidades dos alunos. 


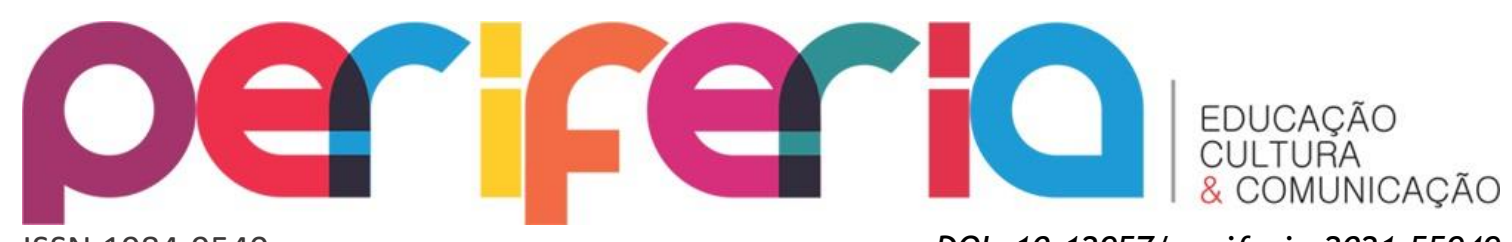

ISSN:1984-9540

DOI: $10.12957 /$ periferia. 2021.55949

Portanto, aquilo que é ensinado nas instituições de ensino superior já não segue mais um padrão nacional, mas é determinado pela demanda do mercado e, assim como na educação básica, o processo de ensino torna-se utilitarista, oferecendo aos alunos os conhecimentos que necessitam para se inserir no mercado de trabalho, ou então, manter a vaga que já possuem, de modo que

o velho modelo de graduação tem sua morte decretada em nome da racionalização econômica que articula a um mercado que tem demandas cada vez mais reduzidas em termos de pessoal e cada vez mais diversificada em termos de formação. As diretrizes esboçadas pelas comissões de especialistas, nessa linha, propõem a redução dos conteúdos obrigatórios, básicos e específicos, a par da criação de ênfases e opções entre percursos e disciplinas que reinventam a taylorização, agora pós-moderna, com a justificativa de flexibilização, que substituirá a formação já insuficiente, por "percursos" aligeirados, mas de baixo custo que satisfarão a demanda por formação superior (KUENZER, 1999, p. 179).

Vemos com as discussões feitas por Kuenzer que os quatro pilares da educação, mencionados no relatório elaborado por Jacques Delors também se revelam no ensino superior brasileiro, uma vez que, há um esvaziamento de conteúdos e valorização do "aprender a aprender", dado o aligeiramento dos "percursos" e do aprender a fazer, exigido nos diversos tipos de formação, assim como a busca pela redução dos custos do ensino superior.

Ao debater as políticas de formação docente presentes na LDB, dentre elas a homologação e regulamentação dos Institutos Superiores de Educação, Kuenzer (1999, p. 181) continua afirmando que:

Formação aligeirada e de baixo custo, a concentrar formação específica e formação em espaço não- universitário, que pode terceirizar a realização de cursos ou a força de trabalho, ou até mesmo ser virtual. Assim, o governo responde à demanda de formação em "nível superior" de um grande contingente de professores para cobrir as necessidades de universalização do Ensino Fundamental e de expandir, na medida dos recursos disponíveis, uma versão secundarista e propedêutica, portanto barateada de Ensino Médio. 


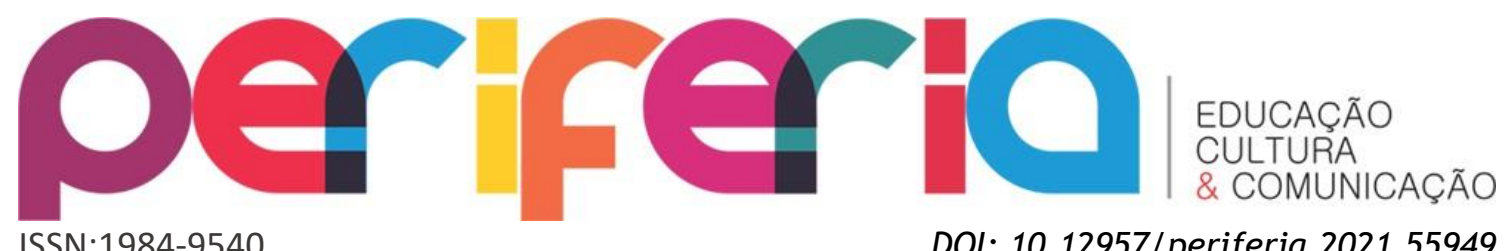

Aqui nos deparamos com uma das grandes contradições da expansão da escolarização brasileira: o Governo incentiva e deseja o aumento dos níveis de escolaridade da população, uma vez que o desenvolvimento econômico não se sustenta com mão de obra pouco qualificada, porém, não investe de forma adequada na educação seja ela em nível básico ou superior. Em consequência, acaba transferindo para a iniciativa privada a responsabilidade pela formação dos indivíduos, que com a flexibilidade que lhe é dada, oferece cursos com baixo nível de qualidade, situação que se agrava ainda mais com a educação à distância.

Por tudo isto, ao analisarmos os níveis de escolarização dos professores do Estado de São Paulo temos que estar conscientes de que eles foram certificados pelo MEC, porém, esta certificação não garante que tenham recebido uma formação adequada que lhes permitam exercer o magistério da melhor maneira, visto que, o aligeiramento dos cursos de formação docente, a formação à distância e o barateamento dos custos podem indicar um enxugamento da grade curricular e contratação de profissionais pouco qualificados para atuarem nestes cursos.

\section{Considerações finais}

Já em busca de conclusões, podemos afirmar que a necessidade de formação específica para os professores que atuam nas escolas do campo é questão conhecida nos debates educacionais, visto que se mostrou presente durante todo o século XX e ainda está em evidência no início do século XXI. Nas primeiras décadas do século XX, a partir dos debates do Ruralismo Pedagógico, esse professor formado especificamente para o trabalho nas escolas rurais era considerado importante ferramenta para a manutenção da população nas áreas rurais. Entretanto, a educação por si só não teria - e não tem — condições de conter um movimento de ordem social e econômica, uma vez que as pessoas abandonavam as áreas rurais em direção às urbanas por motivos às vezes alheios as suas vontades, em busca de melhores condições de vida e trabalho, por exemplo.

Embora o Ruralismo Pedagógico tenha perdido força ao longo dos anos, sua influência ainda se faz presente em movimentos como o dos Trabalhadores Rurais sem Terra e Por uma Educação Básica do Campo, que não só tem debatido a necessidade de formação de professores específicos para as escolas do campo, mas 


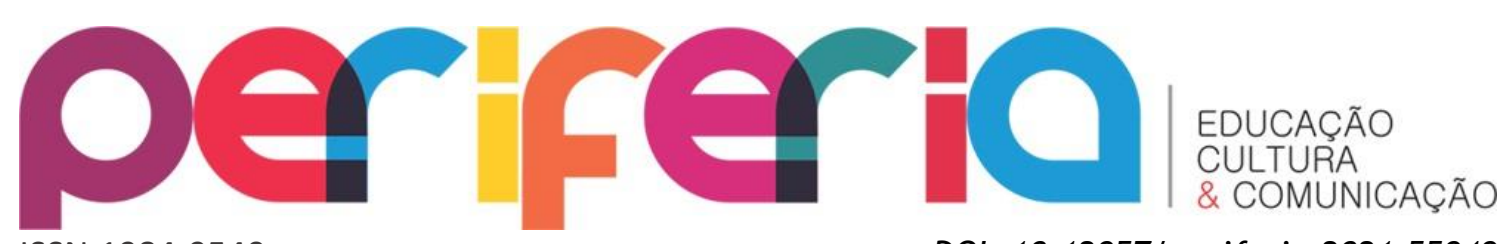

ISSN:1984-9540

DOI: $10.12957 /$ periferia.2021.55949

têm empreendido iniciativas nesse sentido, como as do Instituto de Educação Josué de Castro, os Cursos de Pedagogia da Terra e as Licenciaturas em Educação do Campo, que também são resultantes das lutas das populações do campo pela educação do campo em nível superior.

Quanto aos níveis de certificação docente, sabemos que eles incidem sobre as condições de trabalho do professorado. Os indicadores analisados evidenciaram que embora existam ressalvas quanto à qualidade da formação docente, no ano de 2010, os professores paulistas, tanto das cidades quanto do campo, apresentam altos níveis de certificação, o que coloca a educação no campo paulista em situação vantajosa. Principalmente se comparada à realidade nacional do início da década de 2000 , da qual depreende-se progressos no processo de formação daqueles professores que atuam no campo, mesmo que não seja a formação específica pretendida pelos movimentos sociais do campo.

Deste modo, podemos concluir que ocorreram avanços, de modo geral, nas condições de formação de professores que atuam nas escolas do campo, do início do século XX para cá (2020). Entretanto, iniciativas específicas, identificadas com o trabalho e as lutas daqueles que vivem no campo ainda são pontuais e resultantes das lutas dos movimentos sociais do campo, que ganharam força sobremaneira a partir de meados da década de 1980, portanto em um período histórico recente.

\section{Referências}

BASSO, Jaqueline Daniela. As escolas no campo e as salas multisseriadas no estado de São Paulo: um estudo sobre as condições da educação escolar. 2013. $155 f$. Dissertação (Mestrado em Educação) - Universidade Federal de São Carlos, Programa de Pós-Graduação em Educação, São Carlos/SP, 2013. Disponível em: https://repositorio.ufscar.br/bitstream/handle/ufscar/2650/4997.pdf?sequence=1 tisAllowed=y Acesso em: 08 out. 2019.

BASSO, Jaqueline Daniela. O Ruralismo Pedagógico no estado de São Paulo nas Décadas de 1930 e 1940: as Escolas Normais, os Cursos de Especialização, as Escolas Técnicas e os Clubes Agrícolas. 2018. 202f. Tese (Doutorado em Educação) Universidade Federal de São Carlos, Programa de Pós-Graduação em Educação, São Carlos/SP, 2018. Disponível em: https://repositorio.ufscar.br/handle/ufscar/9843 Acesso em: 08 out. 2019.

BEZERRA NETO, Luiz. A educação escolar rural no estado de São Paulo entre 1890 e 1970: breve discussão sobre o ruralismo pedagógico. HISTEDBR On-line, Campinas, 


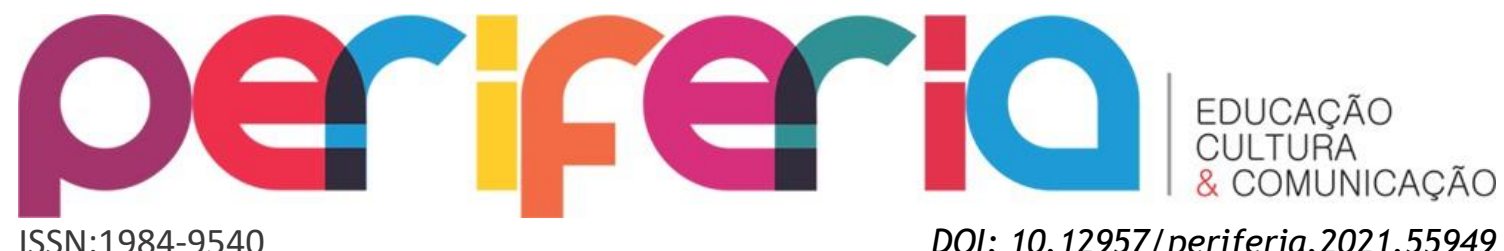

n. 50 (especial), p. 63-76, mai. 2013. Disponível em:

https://periodicos.sbu.unicamp.br/ojs/index.php/histedbr/article/view/8640294 Acesso em: 30 out. 2020.

BEZERRA NETO, Luiz. Sem terra aprende e ensina: um estudo sobre as práticas educativas e formativas do Movimento dos Trabalhadores Rurais Sem Terra - MST 1979-1998.161p. Dissertação (Mestrado em Educação) - Faculdade de Educação, Universidade Estadual de Campinas, Campinas, 1998.

BEZERRA NETO, Luiz. Avanços e retrocessos da educação rural no Brasil. 2003. 221p. Tese (Doutorado em Educação) - Faculdade de Educação, Universidade Estadual de Campinas, Campinas, 2003.

BOF, Alvana Maria (Org.). A educação no Brasil rural. Brasília, INEP, 2006. 233p. Disponível em: http://www.gepec.ufscar.br/textos-1/teses-dissertacoes-etccs/livro-a-educacao-no-brasil-rural/view Acesso em: 02 jun. 2012.

BRASIL. Ministério da Educação e Cultura. Lei de diretrizes e bases da educação nacional. Brasília, 1996. Disponível em:

http://portal.mec.gov.br/seed/arquivos/pdf/tvescola/leis/lein9394.pdf Acesso em: 05 mai. 2012.

CASAGRANDE, Nair. Pedagogia socialista e a formação do educador do campo no século XXI: as contribuições da pedagogia da terra. 296 p. Porto Alegre, RS, 2007. Tese (Doutorado em Educação). Programa de Pós Graduação em Educação, Universidade Federal do Rio Grande do Sul, 2007. Disponível em:

http: / / www.lume.ufrgs.br/bitstream/handle/10183/12204/000624307.pdf?sequen ce=1 Acesso em: 29 mai. 2012.

GAMBOA, Silvio Sánchez. Quantidade - Qualidade: para além de um dualismo técnico e de uma dicotomia epistemológica. In: GAMBOA, Silvio Sánchez; SANTOS FILHO, Camilo dos (Org.). Pesquisa educacional: quantidade - qualidade. 7. ed. São Paulo: Cortez, 2009. p. 84-110. (Coleção Questões da Nossa Época, v.42).

GIL, Antonio Carlos. Como elaborar projetos de pesquisa. 4. ed. São Paulo: Atlas, 2002.

GONSAGA, Eliana Aparecida. Pedagogia da terra: 0 curso de Licenciatura em Educação do Campo de Minas Gerais. Niterói, RJ, 2009. 159p. Dissertação (Mestrado em Educação). Programa de Pós- Graduação em Educação, Universidade Federal Fluminense, Niterói, RJ, 2009.

KOLLING, Edgar Jorge; NÉRY, Israel José; MOLINA, Mônica Castagna. Por uma educação básica do campo. Vol. I. Brasília: Fundação Universidade de Brasília, 1999.

KUENZER, Acacia Zeneida. As políticas de formação: a constituição da identidade do professor sobrante. Educação e Sociedade [online]. Campinas, vol.20, n.68, p. 163-183, dez. 1999. Disponível em:

http://www.scielo.br/pdf/es/v20n68/a09v2068.pdf Acesso em: 15 out. 2012. 


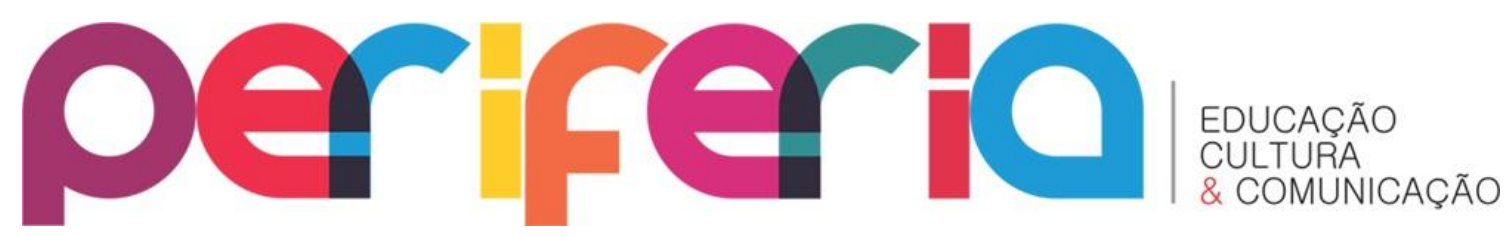

ISSN:1984-9540

DOI: $10.12957 /$ periferia. 2021.55949

MENUCCI, Sud. Discursos e conferências ruralistas. São Paulo: s. ed., 1946. 223p.

INSTITUTO NACIONAL DE ESTUDOS E PESQUISAS EDUCACIONAIS ANÍSIO TEIXEIRA.

Microdados do censo escolar. Disponível em:

http://portal.inep.gov.br/web/guest/basica-levantamentos-acessar Acesso em: 17 mar. 2012.

MOLINA, Mônica Castagna. Contribuições das Licenciaturas em Educação do Campo para as políticas de formação de educadores. Educ. Soc., Campinas, v. 38, n. 140, p. 587-609, jul./set. 2017. Disponível em:

https://www.scielo.br/pdf/es/v38n140/1678-4626-es-38-140-00587.pdf Acesso em: 01 set. 2020.

SOUZA, Rosa Fátima de. Alicerces da pátria: história da escola primária no Estado de São Paulo (1890-1976). Campinas, SP: Mercado das Letras, 2009.

STÉDILE, João Pedro. Prefácio - MST. In: CALDART, Roseli Salete. Educação em movimento: formação de educadoras e educadores no MST. Petrópolis, RJ: Vozes, 1997. p. 9-11. 